\title{
Usefulness of pallidotomy in advanced Parkinson's disease
}

\author{
Folke Johansson, Jan Malm, Erik Nordh, Marwan Hariz
}

\begin{abstract}
Objective-The combined effect of posteroventral pallidotomy and optimal medical treatment was assessed in 22 patients with levodopa sensitive Parkinson's disease.

Methods-Timed motor tests, video recordings, and computer assisted optoelectronic movement analysis were used for serial hourly assessments performed preoperatively and four and 12 months after operation. Tests were made while patients were on optimal medical therapy. Results-There were no serious adverse events of surgery. Two of the 22 patients could not complete all the tests after operation. The proportion of dyskinesia periods decreased in the $\mathbf{2 0}$ patients and there was a proportional increase in normal or fairly normal occasions. "Off" periods were not significantly affected. In 12 of 13 patients with limb dyskinesia this symptom was completely abolished in the contralateral limbs There was also some degree of improvement axially and ipsilaterally. Tremor was moderately improved contralaterally. Bradykinesia remained unchanged. Results at 12 months follow up were similar to those at four months.

Conclusion-Pallidotomy produced a pronounced positive effect on dyskinesia and a moderate effect on tremor. Bradykinesia was not affected. Posteroventral pallidotomy may be useful in patients with Parkinson's disease who have severe motor fluctuations and may allow an increase in levodopa dose to alleviate bradykinesia in "off" states.
\end{abstract}

$(\mathcal{F}$ Neurol Neurosurg Psychiatry 1997;62:125-132)

Feurology

J Malm

Department of Clinical Neurophysiology and Clinical Oral

Physiology

E Nordh

Department of Neurosurgery, University Hospital of Northern Sweden, S-901 85 UMEÅ,

Sweden

M Hariz

Correspondence to:

Dr Folke Johansson

Department of Neurology,

University Hospital of

Northern Sweden, S-901 85

UMEÅ, Sweden.

Received 2 January 1996 and in revised form

1 May 1996

Accepted 31 May 1996
PVP on rigidity, hypokinesia, and tremor were reported, ${ }^{16}{ }^{17}$ together with a reduction in dyskinesia. Favourable results of PVP were also reported by others. ${ }^{18-20}$ However, there were methodological flaws in these early studies ${ }^{21-23}$ although two more recent studies have shown a favourable long term outcome in patients with Parkinson's disease who underwent pallidotomy. ${ }^{24}{ }^{25}$ Another study, however, failed to find an effect in five patients with advanced Parkinson's disease. ${ }^{26}$ Which parkinsonian features improve and to what extent after PVP have not yet been established. ${ }^{27} 28$

In this prospective pilot study, 22 patients with Parkinson's disease with inadequate response to levodopa underwent PVP. Timed tests, video recordings, and computer assisted optoelectronic movement analysis were performed. Serial hourly measurements were made during one day at baseline and four and 12 months after the operation, to evaluate the additional effect of PVP on optimal antiparkinsonian medical therapy, The objective of the study was to evaluate the usefulness of PVP for treating the various symptoms of advanced Parkinson's disease.

\section{Materials and methods}

PATIENTS

In a prospective, consecutive series 21 right handed patients and one left handed patient were included according to the following inclusion criteria: (a) idiopathic Parkinson's disease $^{29}$; (b) documented positive early response to levodopa; (c) insufficient response to pharmacological treatment or severe adverse effects, primarily motor fluctuations; (d) age $<80$ years. Medication was adjusted to maximise the antiparkinsonian efficacy and minimise side effects. Patients had been on stable doses of levodopa for at least two months before entry into the study.

Patients with secondary parkinsonism, multisystem degeneration, prior brain operations (except for Parkinson's disease), and other degenerative or vascular brain diseases were excluded. Patients with advanced cortical atrophy and hydrocephalus on CT were excluded. In one of the 22 patients an asymptomatic prepontine cyst was found on preoperative MRI and another patient had an asymptomatic small calcified parasagittal left sided meningioma at the level of the bregma.

Although some of the patients had experienced transient toxic hallucinations, no patient was psychotic or depressive at the preoperative 
investigations, according to the Unified Parkinson's Disease Rating Scale (UPDRS) part I. ${ }^{30}$

The 22 patients ( 16 men, six women) had a mean age of 63.8 (range 43 to 78 ) years. Duration of Parkinson's disease was $14 \cdot 8$ (range 7 to 22) years and duration of motor fluctuations 7 (range 2 to 11 ) years. The five patients without fluctuations had a shorter duration (mean 10 years) of disease than those with fluctuations (mean 16 years). The median score of the Hoehn and Yahr stage ${ }^{30}$ (in "best on") was 3.0. The mean score (in "best on") of activities of daily living (Schwab and England) ${ }^{30}$ was 72 (range 60 to 80 ) $\%$.

The following laboratory tests were performed to rule out other serious diseases: full blood count, erythrocyte sedimentation rate, tests of hepatic, renal, and thyroid function, blood glucose, serum electrolytes, B12/folic acid, protein electrophoresis, CSF protein, cell count, and ECG.

All patients were on levodopa therapy. Slow release preparations (Madopar HBS or Sinemet SR) alone or in combination with standard levodopa were used in 16 patients. Many patients were on soluble levodopa for rapid effect in off stages or as a booster dose in the morning. Bromocriptine and selegiline were taken by 18 and 11 patients respectively. Two patients had apomorphine in subcutaneous injections and four other patients had tried apomorphine or levodopa infusions without benefit. One patient took anticholinergic drugs for tremor and three patients had amantadine. Three patients had prior experience with protein modulated diets. One patient had had a thalamotomy for tremor seven years before the study and another patient a pallidotomy for dystonia and tremor one year previously. Both patients underwent PVP in the contralateral hemisphere. Postoperatively, the patients were allowed to adjust their Parkinson's disease medication if necessary.

\section{PREOPERATIVE AND POSTOPERATIVE}

INVESTIGATION

At the baseline visit, clinical characteristics were assessed through a neurological examination and careful history, together with an ophthalmological examination including visual fields and acuity. Magnetic cortex stimulation was carried out to screen for corticospinal lesions. ${ }^{3132}$ A short psychometric test $^{33}$ was administered. The mean score was 34.0 (SD 2.7) points (maximum score 40 points). None of the patients fulfilled the criteria for dementia.

Tests for motor performance were carried out during one day, from 800 am to $700 \mathrm{pm}$, at baseline and at four and 12 months postoperatively. Testing was carried out by a trained physiotherapist, who also checked that the patients followed their usual stable drug regimen during the test day.

The study protocol was approved by the local ethics committee. The patients gave their consent after information about the operation and possible adverse effects.
VARIABLES OF SURGICAL OUTCOME

Timed motor tests

Two tests for dexterity of each hand (pronation-supination test and peg board test) and a gait velocity test $(3 \times 10 \mathrm{~m}$ with turns $)$ were performed. The three tests were repeated twice, at 1100 am and $300 \mathrm{pm}$ and the mean time for each test was calculated.

\section{Video recordings}

These were performed every other hour (six times) from 800 am to $600 \mathrm{pm}$. The following items from the UPDRS part III and IV $^{30}$ were evaluated: resting tremor, dyskinesia (disability), rapid finger movements, rapid alternating hand movements, rising from a chair, posture, and gait.

The patients' performance recordings were independently rated by one of us (FJ) and by a physiotherapist who had not taken part in the recordings or examinations. For each limb and axial structures, UPDRS items were scored 0 (absent) to 100 (most severe) using a visual analogue scale (VAS) without predefined steps. ${ }^{34}{ }^{35}$ The VAS scale is both sensitive and reproducible and has equal power compared with a verbal rating scale. ${ }^{36}$ The VAS is an ordinal scale and each score was transferred into one of 10 groups $(0-9,10-19$, $20-29 . . .90-100)$. Every patient was recorded on video six times each test day and the median and maximal values were calculated for each UPDRS item.

\section{Motor fluctuations}

The fluctuations were calculated as percentage of the day and rated in the following categories: "on" time (good or fairly good mobility), "on plus" time (mobile with dyskinesiae) and "off" time (slow or absent mobility). These observations were made every $30 \mathrm{~min}$ utes from 800 am to $700 \mathrm{pm}$ by the same physiotherapist who performed the other motor tests.

The posturolocomotion manual (PLM) test

This test has been designed to objectively quantify selected aspects of a subject's motor performance during a standardised motor task, and can be performed on all freely moving patients with Parkinson's disease of Hoehn and Yahr grade 4 or less. ${ }^{37}$ The rationale is intended to accurately determine the capacity of four different aspects of motor performance: the postural $(\mathrm{P})$, the locomotive $(\mathrm{L})$, and the manual $(\mathrm{M})$ components, and overall movement time (MT). To this end subjects were fitted with six retroreflective markers positioned on the head, shoulder, elbow, hip, and both feet. The movements of these markers were recorded by a specialised high accuracy videocamera based system (MacReflex, Qualisys AB, Partille, Sweden). The patients were instructed to move an object as rapidly as possible from a marked spot on the floor $1.5 \mathrm{~m}$ forwards and place it on a shelf, individually adjusted to the level of the shoulder. These movements were repeated as rapidly as possible during a 30 second test period, and each side was tested. This test sequence was 
repeated every other hour from 900 am to $700 \mathrm{pm}$; in total six times over the 10 hour period. At the subsequent analyses, four different durations of the standardised movement were determined; the movement time from lifting the object to placing it on the shelf (MT); the time taken to raise the body to an upright position ( $P$ phase), the time for the actual forward body movement (L phase), and the time taken to lift the arm ( $M$ phase). Also the number of lifts performed during each 30 second test were determined and a simultaniety index (SI; defined as $\mathrm{P}+\mathrm{L}+\mathrm{M} / \mathrm{MT}$ ), which is intended to quantify how well the PLM phases are coordinated into a smooth motor act, were computed. For the present report, only the estimates of total MT and SI were evaluated.

\section{SURGICAL PROCEDURE}

Fifteen PVPs were carried out in the left hemisphere and nine in the right. Two patients were reoperated on as described below. All patients underwent a stereotactic CT or stereotactic MRI study, one to three days before surgery, using the Laitinen stereoadapter. ${ }^{16}$ The length of the intercommissural line was measured and the standard pallidal target was defined $2 \mathrm{~mm}$ in front of the midcommissural point, $5-6 \mathrm{~mm}$ below the intercommissural line, and $20-22 \mathrm{~mm}$ lateral to the midline of the third ventricle. This point represented the zero point-that is, the most ventral point of the target area to be stimulated and eventually coagulated.

To maximise the symptoms at the time of surgery, all parkinsonian medication was stopped at least 12 hours before pallidotomy. For surgery, the stereoadapter was repositioned on the head while the patient was in a semisitting position on the operating table. Around it, Laitinen's stereoguide was mounted rigidly on the skull under local anaesthesia. Thereafter the patient was laid supine on the table. The CT/MRI coordinates of the pallidal target were transferred to the stereoguide and the stereoadapter was removed.

Through a frontal burr hole lying $2-3 \mathrm{~cm}$ from the midline, slightly in front of the coronal suture, a $1.8 \mathrm{~mm}$ thick monopolar electrode with a $2 \mathrm{~mm}$ long non-insulated tip was introduced towards the target under impedance monitoring. Electrical stimulations were conducted with $6 \mathrm{~Hz}, 10 \mathrm{~mA}$ and $60 \mathrm{~Hz}, 5 \mathrm{~mA}$ at $2 \mathrm{~mm}$ intervals, between the ventral most edge of the pallidum, represented by the zero target point, and the level of the intercommissural line estimated to lie $6 \mathrm{~mm}$ dorsal to that point. During stimulation, care was taken to detect any capsular or visual response. In addition, speech and articulation were carefully monitored. The patient was asked to perform bicycling movements, alternating hand movements, and finger agility movements. The orientation and short term memory of the patient were checked. These same tasks were also performed during coagulation at each of the points.

If stimulation did not give rise to any unde- sirable reactions an incremental radiofrequency lesion was produced by heat coagulation at $75-83^{\circ} \mathrm{C}$ during $30-60$ seconds in steps of $2 \mathrm{~mm}$ between the zero point and a point 6-8 $\mathrm{mm}$ dorsal. After being applied in 15 patients, this technique was slightly changed in the remaining seven patients: the electrode was first stopped $6 \mathrm{~mm}$ dorsal to the zero target point and then stimulation and coagulation were conducted in a dorsal to ventral direction. In all patients a stereotactic CT or MRI study was conducted 4-10 months after surgery. The scanning plane was made identical to the preoperative radiological study, both for the CT and MRI. Thus the lesion site could be assessed in relation to the preoperative target point-that is, to the reference points of the third ventricle (the intercommissural line, midcommissural point, and midsagittal plane of the third ventricle).

\section{STATISTICAL METHODS}

Preoperative and postoperative variables of the timed tests were evaluated by a paired $t$ test. Ordinal values (for example, from the video recording), were analysed using the Wilcoxon signed rank test. PLM tests were analysed with the Mann-Whitney $U$ test and the KruskalWallis test. Repeated measures analysis of variance (ANOVA) was used to determine the significance of changes in motor fluctuations over time. A significance level of $P \geqslant 0.05$ was used.

\section{Results}

\section{ADVERSE EVENTS DURING OPERATION AND} FOLLOW UP

In patients Nos 3, 15, and 17 capsular responses at stimulation led to a replacement or slight withdrawal of the electrode and to a coagulation of a smaller volume than initially intended. None of the 22 patients had any corticospinal dysfunction at examination or on motor cortex stimulation four or 12 months postoperatively.

In nine patients (40\%), visual responses were obtained at stimulation between the zero target (most ventral point) and up to $4 \mathrm{~mm}$ above the zero target. In these patients, either the electrode was withdrawn and coagulation was made more dorsally (in patients in whom the electrode was first introduced to the zero target), or the coagulation and surgery were interrupted (in patients in whom stimulation and coagulation were started at points dorsal to the zero target). In either case, the lesion was generally placed slightly more dorsally or was smaller than initially planned. In patients Nos 20 and 22 slight confusion or dysarthria occurred during and directly after coagulation respectively. Steroids were given and the symptoms resolved after a few hours.

At the four month follow up, two patients could not be tested for the following reasons: patient No 1 with some cognitive deficit preoperatively developed psychotic symptoms a few months after the operation and was excluded from further analyses. Patient No 12 with severe dysartria and dysphonia preopera- 
Figure 1 Thin slice $M R$ showing the appearance of the lesion in the right pallidum one day after surgery $(A)$ and four months after surgery (B arrow).

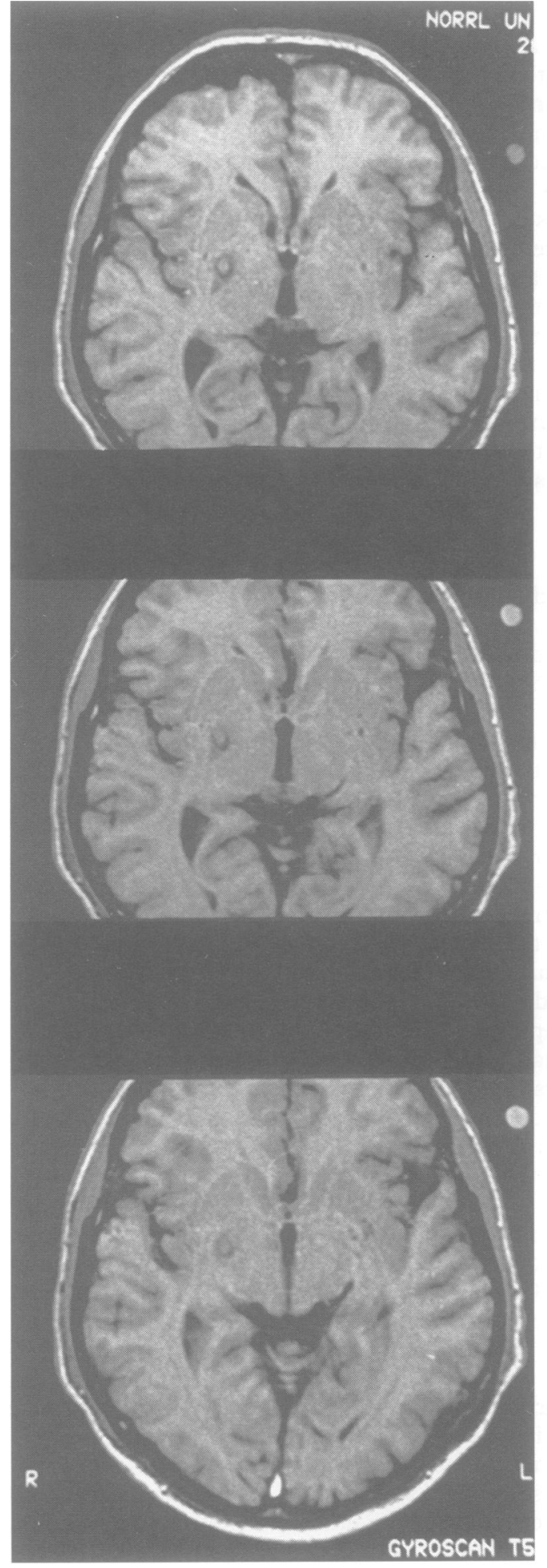

A

tively had almost complete anarthria and also increased gait disturbance after operation and was also excluded from further testing. Patient No 17 developed acute psychosis two months after operation but recovered rapidly on small doses of clozapine without changing Parkinson's disease medication. At 12 months, results from another four patients were missing: patient No 11 developed a malignant glioma eight months after surgery, patient No 13 had a serious traffic injury when riding a motor cycle (!), patient No 2 had cardiac disease, and patient No 10 was not available for administrative reasons. Only. in patient No 12

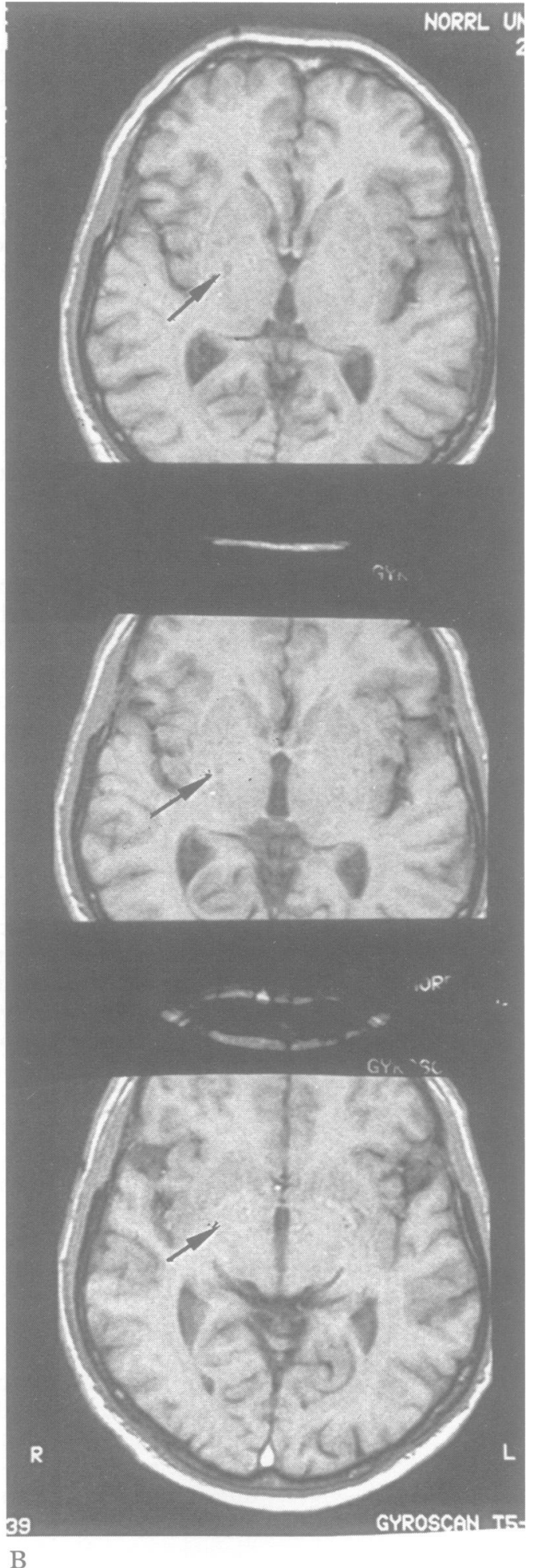

could the symptoms be directly attributed to the operation. Patient No 13 had a permanent but small and subclinical visual scotoma postoperatively.

REOPERATIONS

Dyskinesia recurred postoperatively in patient No 4 and tremor in patient No 9 and had not improved at the evaluation four months postoperatively. Furthermore, their lesions were considered to be small on CT or MRI. Surgery was repeated on the same side 10 and 11 months later. Both patients were evaluated at four months after the first operation and at 
Table 1 Fluctuations in motor performance calculated as percentage of the day

\begin{tabular}{|c|c|c|c|}
\hline & Baseline & 4 months & 12 months \\
\hline & Mean (\%) (95\% CI) & Mean (\%) (95\% CI) & Mean (\%) (95\% CI) \\
\hline $\begin{array}{l}\text { “Off" time } \\
\text { “On" time } \\
\text { “On+" time }\end{array}$ & $\begin{array}{l}23 \cdot 8(14 \cdot 1-33 \cdot 5) \\
18 \cdot 3(10 \cdot 1-26 \cdot 6) \\
57 \cdot 8(45 \cdot 3-70 \cdot 3)\end{array}$ & $\begin{array}{l}27 \cdot 8(18 \cdot 7-36 \cdot 9) \\
46 \cdot 4(32 \cdot 6-60 \cdot 2) \\
25 \cdot 8(14 \cdot 3-37 \cdot 3)\end{array}$ & $\begin{array}{l}27 \cdot 9(18 \cdot 6-37 \cdot 3) \\
41 \cdot 2(26 \cdot 8-55 \cdot 5) \\
30 \cdot 8(16 \cdot 1-45 \cdot 7)\end{array}$ \\
\hline
\end{tabular}

Observations were every 30 minutes from 800 am to $700 \mathrm{pm}$ "On" = good or fairly good mobility; "On plus" = mobile with dyskinesiae, "Off" = slow or absent mobility.

Table 2 Median and maximum values of the six video recordings each test day on the operated side (contralateral to pallidotomy)

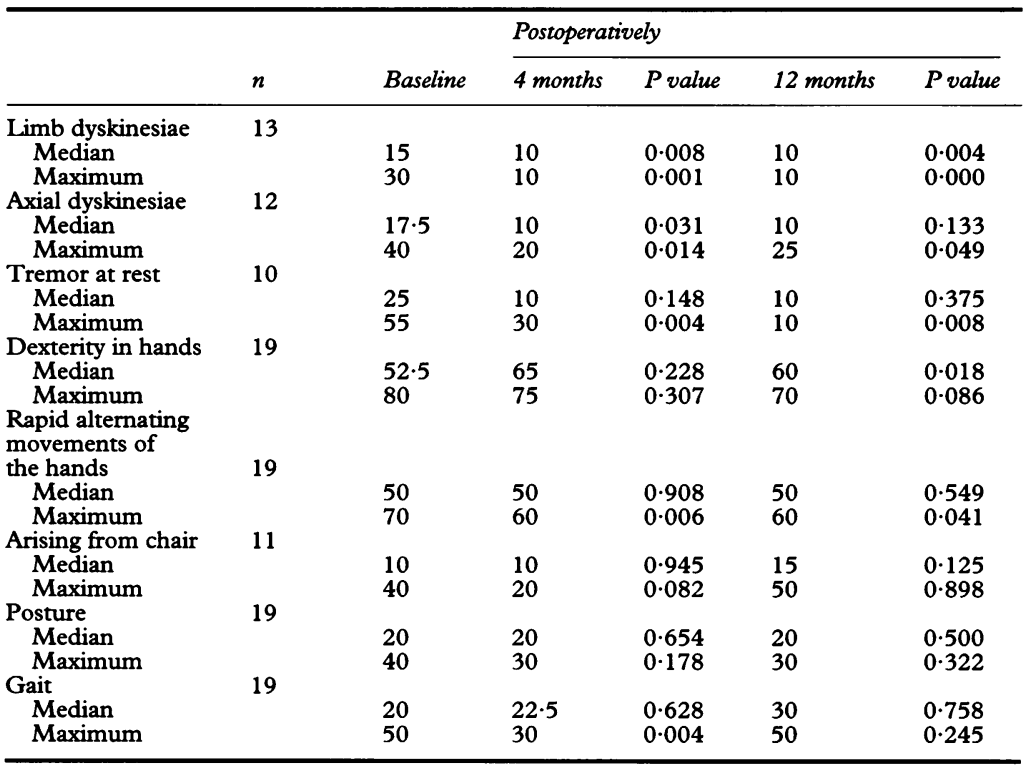

$n$ Refers to number of patients with the symptom.

Table 3 Median and maximum values of the six video recordings on the non-operated side (ipsilateral)

\begin{tabular}{|c|c|c|c|c|c|c|}
\hline & \multirow[b]{2}{*}{$n$} & \multirow[b]{2}{*}{ Baseline } & \multicolumn{4}{|c|}{ Postoperatively } \\
\hline & & & 4 months & Pvalue & 12 months & Pvalue \\
\hline Limb dyskinesiae & 13 & & & & & \\
\hline Median & & 15 & 10 & 0.001 & 10 & 0.028 \\
\hline Maximum & & 15 & 10 & $0 \cdot 188$ & 10 & 0.312 \\
\hline Tremor at rest & 4 & & & & & \\
\hline Median & & $17 \cdot 5$ & 15 & - & 20 & - \\
\hline$\underset{\text { Dexterity }}{\text { Maximum }}$ & & 40 & 40 & - & 20 & - \\
\hline Dexterity & 19 & & & & & \\
\hline $\begin{array}{l}\text { Median } \\
\text { Maximum }\end{array}$ & & $\begin{array}{l}65 \\
80\end{array}$ & $\begin{array}{l}57 \cdot 5 \\
70\end{array}$ & 0.994 & $\begin{array}{l}50 \\
70\end{array}$ & 0.535 \\
\hline $\begin{array}{l}\text { Rapid alternating } \\
\text { movements of } \\
\text { the hands }\end{array}$ & 19 & & & & & \\
\hline $\begin{array}{l}\text { Median } \\
\text { Maximum }\end{array}$ & & $\begin{array}{l}50 \\
60\end{array}$ & $\begin{array}{l}50 \\
50\end{array}$ & $\begin{array}{l}0.413 \\
0.094\end{array}$ & $\begin{array}{l}47 \cdot 5 \\
50\end{array}$ & $\begin{array}{l}0.510 \\
0.063\end{array}$ \\
\hline
\end{tabular}

$n$ Refers to number of patients with the symptom.

four and 12 months after reoperation. Results have been calculated on each of these follow up combinations. The results did not affect the group mean.

POSITION AND SIZE OF THE LESIONS

The lesion size as measured on CT (four months after operation) was $65.5 \mathrm{~mm}^{3}(95 \%$ confidence interval $(95 \% \mathrm{CI}) 44 \cdot 9-86 \cdot 1)$ in the 22 patients. Two patients with very small lesions were reoperated on and the corresponding group mean volume was $72 \cdot 3(95 \%$ CI $50.9-93.7) \mathrm{mm}^{3}$ including these operations. Fifteen of the 22 patients also underwent a stereotactic MRI study four months after surgery. The mean volume of the MRI lesion was $72 \cdot 8(95 \% \mathrm{CI} 46 \cdot 8-101 \cdot 8) \mathrm{mm}^{3}$.

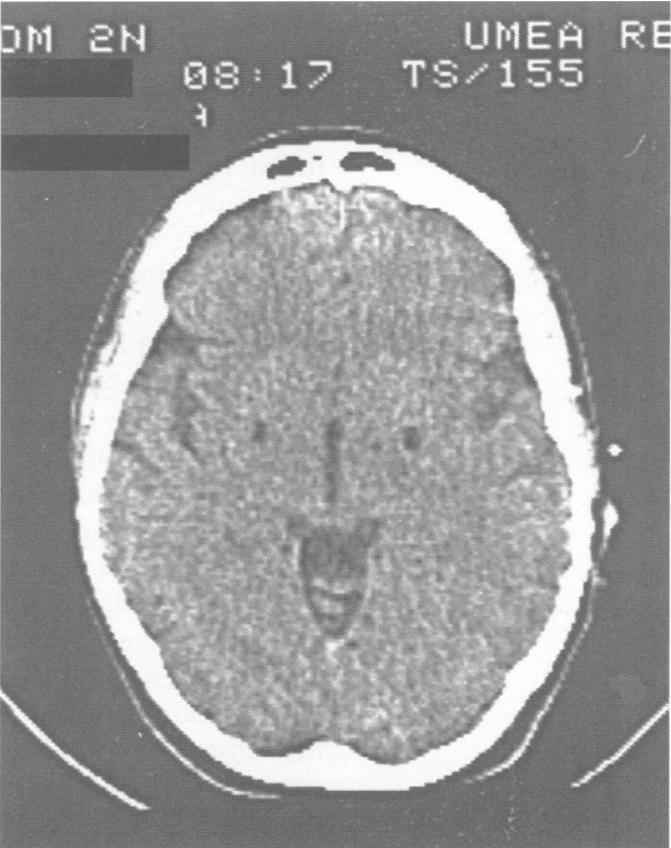

Figure 2 Bilateral pallidotomies in one patient done in two different centres by two different neurosurgeons at a one year interval (first surgery in right pallidum).

The lesion, which was estimated to be $4-6$ $\mathrm{mm}$ in transversal diameter with a rostrocaudal length of $6-8 \mathrm{~mm}$, was $<95 \%$ CI $\left(<46.8 \mathrm{~mm}^{3}\right)$ in nine patients $(41 \%)$ and $>95 \%$ CI $\left(>101.8 \mathrm{~mm}^{3}\right)$ in four patients $(19 \%)$. There was no clear correlation between the size of the coagulated area and the size of the final lesion (fig $1 \mathrm{~A}$ and $\mathrm{B}$ ). The estimated location of the lesion coincided with the coagulated pallidal area in all patients. In nine patients the coagulated area lay more dorsal to the intended zero point target (ventralmost edge of pallidum) because of an optic response at stimulation as reported previously.

\section{MEDICATION}

Daily doses of levodopa during the study were: baseline, 952 (SD 365) mg; four months, 913 (SD 377) mg; 12 months, 931(SD 373) mg. The corresponding doses of bromocriptine were: baseline, 18.2 (SD 14.3) $\mathrm{mg}$; four months, $19 \cdot 7$ (SD 15.1) mg; 12 months, $21 \cdot 4$ (SD 15.4$) \mathrm{mg}$. There were no significant changes in these treatments during the study period. Selegiline and the other Parkinson's disease medications were also unchanged.

\section{FOLLOW UP AT FOUR MONTHS}

Motor fluctuations

A repeated measures ANOVA (motor fluctuations and follow up time) was performed to study differences in fluctuations in motor performance before and after operation. There was a significant interaction effect between the two factors $(F=7 \cdot 2 ; \mathrm{P}<0.003)$. Table 1 gives the means. In summary, the proportion of "on plus" occasions decreased considerably at four months and there was a proportional increase in the proportion of "on" occasions (table 1). The proportion of "off" occasions did not vary significantly during the study period. 
Video recordings

Because of technical errors, one patient (No 11) was not video recorded at four months. Table 2 summarises the median and maximum values of the UPDRS items at baseline and four months after operation. The most prominent finding was a reduction of dyskinesiae on both the operated and non-operated sides (tables 2 and 3 ). In 12 patients (out of 13) who had dyskinesiae preoperatively, these had completely vanished four months after operation. The only patient (No 20), who did not improve doubled her levodopa dose postoperatively, which might explain the negative result in this case. The maximum values of axial dyskinesia and tremor were significantly decreased postoperatively and there was a tendency, however not significant, towards improvement in the median values (table 2 ). The maximum values of rapid alternating movements of the hands and gait were significantly decreased postoperatively, but not the median values. The items rising from a chair and posture did not change after the operation. Patients with freezing were not improved.

\section{Timed motor tests}

Preoperatively, the mean time of the pegboard test was 44 (range 28-60) seconds and of the pronation-supination test 52 (range 17-173) seconds on the operated side. The mean time of the gait velocity test was 27 (range 16-41) seconds. No significant changes were found at four months compared with preoperative scorings, neither on the operated nor on the nonoperated side.

\section{Optoelectronic movement analyses}

A total of 231 test sequences containing 994 standardised lifting movements were analysed at baseline and 231 tests/1028 lifts at four months. In patient No 2 no recording could be made at the four month follow up. There were no significant differences between the right/left side and between operated/non-operated sides, in recorded MT and SI estimates for individual patients at any of the observation occasions (Kruskal-Wallis and Mann-Whitney tests). In addition, no significant changes in MT or SI could be detected postoperatively, either when the overall data including all tests during the day were assessed or if a subgroup containing data with the selected longest MT of the day were analysed (Mann-Whitney test). However, when compared with the preoperative values, there was a significant increase in the average number of performed lifting movements per test sequence (MannWhitney, $P=0.02$ ).

\section{FOLLOW UP AT 12 MONTHS}

\section{Motor fluctuations}

Table 1 gives the mean percentage of motor fluctuations. Compared with the preoperative investigation, the proportion of "on plus" occasions decreased considerably and there was an increase in the proportion of "on" occasions. The proportion of "off" occasions did not change. Compared with the results at four months, there were no changes.

\section{Video recordings}

Table 2 summarises the median and maximum values of the UPDRS items at baseline and 12 months postoperatively. The results were similar to those at four months. There was a reduction in limb dyskinesia in both the operated and non-operated sides (tables 2 and 3 ). On the operated sides, the maximum values of tremor, axial dyskinesiae, and rapid alternating movements of the hands were significantly decreased postoperatively. There was a tendency (non-significant), towards improvement in the median values of tremor and axial dyskinesia (table 2). There were no significant differences before and after operation in the items gait, arising from chair, and posture. Patients with freezing were not improved.

\section{Timed motor tests}

No significant changes were found at 12 months compared with preoperative scores or to the scores at four months, neither on the operated nor on the non-operated side.

Optoelectronic movement analyses

A total of 230 test sequences containing 879 standardised lifting movements were analysed. There were no significant differences between the right/left side and between operated/ non-operated sides in recorded MT and SI estimates at individual patient data level (Kruskal-Wallis and Mann-Whitney tests). In addition, no significant changes in MT or SI could be detected 12 months postoperatively, even when the overall data including all tests during the day or a subgroup containing data with the selected longest MT of the day were analysed (Mann-Whitney test). The increase in the average number of performed lifting movements per test sequence found at four months could not be confirmed.

\section{Discussion}

In this prospective long term study we confirmed other reports of a beneficial effect of PVP on tremor and dyskinetic movements. ${ }^{16-20} 24-263839$ The effect on tremor was moderate but very pronounced on dyskinesiae, especially contralaterally but also on axial structures and ipsilaterally. The patients had a better quality of "on-off" fluctuations postoperatively with a significant increase in the number of more normal "on" phases and reduction in the number of "on" phases with dyskinesiae.

The number of "off" phases, however, did not change significantly and contrary to most earlier reports, ${ }^{16-2024254041}$ we could not find any consistent improvement in bradykinesia or gait disturbance over time. Our negative results in this respect are in line with those in a small group of five patients with nine operative procedures. ${ }^{26}$ As in a recent report, we were also unable to find any improvement in freezing of gait. ${ }^{25}$ The PLM method, which has proved its value as a sensitive indicator of changes in 
bradykinesia in Parkinson's disease, ${ }^{37}$ 42-44 $^{\text {did }}$ not show any significant changes in MT or SI of the standardised tasks in the present study. The reasons for this may be twofold. Firstly, the defined task involved a movement which includes a visually guided reaching task, and it may well be that this motor act is less influenced by the dyskinetic components, which are clearly reduced by the PVP. Secondly, the algorithms of the PLM test are mainly focused on the duration of the motor act and timing of the subparts. Pseudorandom deviations in space from the "ideal" movement path, which is one characteristic of dyskinetic behaviour, might not be optimally monitored and quantitately assessed by the PLM method. The present finding, of a significant postoperative increase in the average number of lifting movements per test sequence, could indicate a more efficient performance with less time spent on movements unrelated to the particular task.

Previous reports ${ }^{16-20} 3839$ have shown that PVP has a great positive effect on almost all symptoms and signs in Parkinson's disease; bradykinesia, rigidity, tremor, gait and voice disturbance, balance, freezing, and also on $\mathrm{ADL}$ and psychiatric functions. However, the preoperative and postoperative data on the patients and methods are insufficient to make such far reaching conclusions, ${ }^{21-23}$ and the long lasting benefit of pallidotomy still remains to be proved. ${ }^{27} 2845$

Recent results from elsewhere ${ }^{24}{ }^{25}$ can be compared in many aspects with those in the present study. Important information is given in these other two studies, that the motor improvement was significantly better in the worst off condition (12 hours off medication) than in the best on condition after medication. One study ${ }^{25}$ indicated that there was no significant difference in blinded and non-blinded scorings of motor performance preoperatively and postoperatively in the on states. The best on conditions are more like the hourly rated Parkinson's disease conditions in the present study than the 12 hours off medication states.

The right or optimal size and location of the pallidal lesion are factors of probably great importance for the outcome of the operation, but the optimal lesion site and size remain uncertain. ${ }^{45}$ The locations of the PVPs in the present case series were in close vicinity to the target suggested by Svennilson et $a l^{15}$ and Laitinen et al.1617 This is illustrated in fig 2 (patient No 21), where a right sided PVP by Laitinen one year before inclusion can be compared with a left sided PVP in this study. The anatomical location of the lesions is similar in both hemispheres. Dogali et $a^{24}$ used microelectrode registration to locate the pallidal target and claimed that all lesions were within one $\mathrm{mm}$ of the intended target. However, on the coronal MRI illustrating the pallidotomies (figure 2a on page 755 of Dogali et $\mathrm{al}^{24}$ ) it is clear that this lesion is too far anterior compared with the target suggested by Laitinen and Leksell. The optic chiasm, which is visible on the slice, lies ventral and slightly anterior to the anterior commisure, but the intended target according to Laitinen and Leksell lies in the coronal plane, 9-11 mm behind the level of the anterior commisure. Perhaps such a different location of the pallidal lesion might explain the better effect on bradykinesia in the study by Dogali et al. ${ }^{24}$

In conclusion, we confirmed a large effect of posteroventral pallidotomy on dyskinesiae and a moderate effect on tremor. However, with our evaluation methods, we could not find any significant additional effect on bradykinesia in patients who already had optimal medication for Parkinson's disease. Because levodopa induced dyskinesiae are clearly improved by the operation, pallidotomy could be an alternative for patients with severe motor fluctuations, thereby permitting further increase of levodopa to alleviate bradykinesia in off phases. On the other hand, pure akinetic rigid Parkinson's disease syndromes, with or without motor blocking (freezing), may not benefit from pallidotomy, except moderately for tremor.

We thank Britta Lindström for technical assistance and Eva Johansson for evaluation of the videotapes. The study was supported by the Karl-Oskar foundation and the Swedish Society of the Neurologically Disabled (NHR).

1 Marsden CD. Parkinson's disease. I Neurol Neurosurg Psychiatry 1994;57:672-81.

2 Olanow C, Marsden C, Lang A, Goetz C. The role of surgery in Parkinson's disease management. Neurology 1994;44(suppl 1):S17-20.

3 Goetz C, DeLong M, Penn R, Bakay R. Neurosurgical horizons in Parkinson's disease. Neurology 1993;43:1-7.

4 Diedrich N, Goetz C, Stebbins G, et al. Blinded evaluation confirms long-term asymmetric effect of unilateral thalamotomy or subthalamotomy on tremor in Parkinson's disease. Neurology 1992;42:1311-14.

5 Tasker RR. Tremor of parkinsonism and stereotactic thalamotomy. Mayo Clin Proc 1987;62:736-9.

6 Miles J, Redfern RM. The place ot thalamotomy in the treatment of parkinsonism. Brf Neurosurg 1987;1:311-5.

7 Benabid AL, Pollak P, Louveau A, et al. Combined (thalamotomy and stimulation) stereotactic surgery of the VIM thalamic nucleus for bilateral Parkinson disease. Appl Neurophysiol 1987;50:344-6.

8 Benabid A, Pollak P, Seigneuret E, et al. Chronic VIM thalamic stimulation in Parkinson's disease, essential tremor and extra-pyramidal dyskinesias. Acta Neurochir Suppl (Wien) 1993;58:39-44.

9 Blond S, Caparros-Lefebvre D, Parker F, et al. Control of tremor and involuntary movement disorders by chronic stereotactic stimulation of the ventral intermediate thalamic nucleus. F Neurosurg 1992;77:62-8.

10 Caparros-Lefebvre D, Blond S, Vermersch P, et al. Chronic thalamic stimulation imroves tremor and levodop induced dyskinesias in Parkinson's disease. $\mathcal{f}$ Neurol Neurosurg Psychiatry 1993;56:268-73.

11 Klockgether T, Löschmann P-A, Wüllner U. New medical and surgical treatments for Parkinson's disease. Current Opinion in Neurology 1994;7:346-52.

12 Lindvall $\mathrm{O}$, Widner $\mathrm{H}$, Rehncrona $\mathrm{S}$, et al. Transplantation of fetal dopamine neurons in Parkinson's disease: oneyear clinical and neurophysiological observations in two patients with putaminal implants. Ann Neurol 1992; patients with

13 Widner $H$, Rehncrona S. Transplantation and surgical treatment of parkinsonian syndromes. Curr Opin Neurol Neurosurg 1993;6:344-9.

14 Fahn S. Fetal-tissue transplantation in Parkinson's disease. N Engl J Med 1992;327:1589-90.

5 Svennilson E, Torvik A, Lowe R, Leksell L. Treatment of parkinsonism by stereotactic thermolesions in the pallidal region. Acta Neurol Scand 1960;35:358-77.

16 Laitinen L, Bergenheim A, Hariz M. Leksell's posteroventral pallidotomy in the treatment of Parkinson's disease. $f$ Neurosurg 1992;76:53-61.

17 Laitinen L, Bergenheim A, Hariz M. Ventroposterolateral pallidotomy can abolish all parkinsonian symptoms. ptereotact Funct Neurosurg 1992;58(1-4):14-21.

18 Iacono $R$, Lonser $R$. Reversal of Parkinson's akinesia by pallidotomy [letter]. Lancet 1994;343:418-9.

19 Iacono R, Lonser R, Mandybur G, et al. Stereotactic pallidotomy results for Parkinson's exceed those of fetal graft. Am Surg 1994;60:777-82.

20 Iacono $\mathrm{R}$, Shima F, Lonser $\mathrm{R}$, et al. The results, indications, and physiology of posteroventral pallidotomy for patients with Parkinson's disease. Neurosurgery 1995;36: 1118-25.

21 Quinn N. Reversal of Parkinson's akinesia by pallidotomy [letter]. Lancet 1994;343:1095-6. 
22 Unknown. Surgical treatment of Parkinson's disease: a new role for an old treatment? Neurology Alert 1992;11: 54-5.

23 Bakay $R$. The results, indications, and physiology of posteroventral pallidotomy for patients with Parkinson's disease [comments]. Neurosurgery 1995;36:1126-7.

24 Dogali M, Fazzini D, Kolodny E, et al. Stereotactic ventral pallidotomy for Parkinson's disease. Neurology 1995; 45:753-61.

25 Lozano A, Lang A, Galvez-Jimenez N, et al. Effect of GPi pallidotomy on motor function in Parkinson's disease. Lancet 1995;346:1383-7.

26 Sutton J, Couldwell W, Lew M, et al. Ventroposterior medial pallidotomy in patients with advanced Parkinson's disease. Neurosurgery 1995;36:1112-16.

27 Kelly P. Pallidotomy in Parkinson's disease. Neurosurgery 1995;36:1154-7.

28 Tasker R. Ventroposterior medial pallidotomy in patients with advanced Parkinson's disease [comments]. Neurosurgery 1995;36:1116.

29 Calne DB, Snow B, Lee C. Criteria for diagnosing Parkinson's disease. Ann Neurol 1992;32:S125-7.

$30 \mathrm{Fahn} \mathrm{S}$, Elton $R$, and members of the UPDRS. Development Committee. Unified Parkinson's disease rating scale. In: Fahn S, Marsden S, Calne D, Goldstein rating scale. In: Fahn S, Marsden $S$, brain stimulation. Vol 2. London: MacMillan Healthcare, 1987: 153-63.

31 Barker AT, Jalinous R. Non-invasive magnetic stimulation of human motor cortex. Lancet 1985;i:1106-7.

32 Eisen A, Shtybel W. Clinical experience with transcranial magnetic stimulation. Muscle Nerve 1990;13:995-1011.

33 Kokmen E, Naessens JM, Offord KP. A short test of mental status: description and preliminary results. Mayo Clin Proc 1987;62:281-8.

34 Joyce C, Zutski D, Hurbes W, Mason R. Comparison of fixed interval and visual analogue scales for rating chronic pain. Europ f Clin Pharmacol 1976;8:415-20.

35 Scott J, Huskisson E. Measurement of pain. Lancet 1976; ii: $1127-31$

36 Skovlund E, Flaten $\mathrm{O}$. Response measures in the acute treatment of migraine. Cephalalgia 1995;15:519-22.

37 Steg G, Johnels B. Physiological mechanisms and assessment of motor disorders in Parkinson's disease. Vol 60. In: Narabayashi H, Nagatsu T, Yanagisawa N, Mizuino Y, eds. Advances in Neurology. New York: Raven Press, 1993.

38 Laitinen LV. Ventroposterolateral pallidotomy. Stereotact Funct Neurosurg 1994;62:41-52.

39 Laitinen LV. Pallidotomy for Parkinson's disease. Neurosurg Clin N Am 1995;6:105-12.

40 Vitek J, Baron M, Kaneoke Y, et al. Microelectrode-guided pallidotomy is an effective treatment for medically intractable Parkinson's disease [abstract]. Neurology 1994;44(suppl 2):A304.

41 Baron $M$, Turner $R$, Vitek J, et al. Lesions of the interna segment of the globus pallidus (GPi) in parkinsonia patients improve motor performance bilaterally [abstract]. Neurology 1994;44(suppl 2):A304.

42 Johnels B, Ingvarsson PE, Thorselius $M$, et al. Disability profiles and objective quantitative assessment in

43 Johnels B, Ingvarsson P, Matousek M, et al. Optoelectronic movement analysis in Parkinson's disease: effect of selegiline on the disability in de novo parkinsonian patients - a pilot study. Acta Neurol Scand 1991;84 (suppl patients-a

44 Johnels B, Ingvarsson P, Holmberg B, et al. Single-dose Ldopa response in early Parkinson's disease: measurements with optoelectronic recording technique. Mov disord 1991;8:56-62.

45 Bakay R, DeLong M, Vitek J. Posteroventral pallidotomy for Parkinson's disease (letter). $\mathcal{f}$ Neurosurg 1992;77: 487-88. 